\title{
Erratum to: Variable Selection in Joint Mean and Dispersion Models via Double Penalized Likelihood
}

Christiana Charalambous, Jianxin Pan and Mark Tranmer

The University of Manchester, Manchester, UK

Erratum to: Sankhyā B

$$
\text { (10.1007/s13571-014-0079-6) }
$$

In the article, 'Variable Selection in Joint Mean and Dispersion Models via Double Penalized Likelihood' having DOI 10.1007/s13571-014-0079-6, published online on Springerlink, the affiliations of the authors Jianxin Pan and Mark Tranmer were interchanged. Their correct affiliations are as below:

Jianxin Pan

School of Mathematics

The University of Manchester

Manchester M13 9PL, UK

Mark Tranmer

School of Social Sciences

The University of Manchester

Manchester M13 9PL, UK

Springer apologizes to the authors, readers, and the Editorial Board of Sankhya B for this error.

Christiana Charalambous

JIANXIN PAN AND

SChOOL OF Mathematics

The University of Manchester

MANChESTER M13 9PL, UK

E-mail:

Christiana.Charalambous@manchester.ac.uk
MARK TRANMER

School of Social ScIEnces

The University of Manchester

MANChESTER M13 9PL, UK 